\title{
Reflorestamento de manguezais e o valor de resgate para o seqüestro de carbono atmosférico
}

\section{The reforestation of mangrove swamps and its value in atmospheric carbon sequestration}

\author{
Sérgio de Mattos Fonseca \\ Associação de Proteção de Ecossistemas Costeiros (APREC) \\ Rua Dr. Macário Picanço, 825 (antiga rua 54) \\ 24342-330 Niterói - RJ Brasil \\ sergio@aprec.org.br \\ José Augusto Drummond \\ Centro de Desenvolvimento Sustentável, Universidade de Brasília \\ SQN 304, Bloco D, ap. 507 \\ 70736-040 Brasília - DF Brasil \\ jaldrummond@uol.com.br
}

FONSECA, S. de M. E DRUMMOND, J. A.: 'Reflorestamento de manguezais e o valor de resgate para o seqüestro de carbono atmosférico'. História, Ciências, Saúde-Manguinhos, vol. 10(3): 1071-81, set.-dez. 2003.

Os autores afirmam a relevância do reflorestamento de manguezais para projetos de seqüestro de carbono atmosférico, dentro dos princípios do chamado mecanismo de desenvolvimento limpo (MDL), definidos em diversas arenas técnicas e políticas internacionais, dentro da Convenção de Mudanças Climáticas. Descrevem um projeto de pesquisa em andamento, que inclui estudo de caso focalizado em manguezais da laguna de Itaipu (Niterói, RJ), cujo objetivo é selecionar e fazer medições preliminares de parâmetros ecológicos e socioambientais relevantes para a valoração econômica e financeira dos benefícios do reflorestamento. A seleção e as medições servirão como estudo de viabilidade para que projetos semelhantes se qualifiquem para obter apoio financeiro e alcançar sucesso técnico, gerando benefícios ambientais e sociais.

PALAVRAS-CHAVE: efeito estufa, seqüestro de carbono, manguezais, mecanismo de desenvolvimento limpo, mudanças climáticas, IPCC.

FONSECA, S. de M. E DRUMMOND, J. A.: 'The reforestation of mangrove swamps and its value in atmospheric carbon sequestration'. História, Ciências, Saúde - Manguinhos, vol. 10(3): 1071-81, Sept.-Dec. 2003.

The article argues that the reforestation of mangrove swamps is of relevance to projects for sequestering atmospheric carbon, within the principles of the Clean Development Mechanism (CDM) currently being defined in different technical and political arenas as part of the Convention on Climate Change. The text describes a research project currently under way that includes a case study of mangrove swamps in the Itaipu Lagoon in Niterói, RJ. The project's goal is to select and take preliminary measurements of the ecological and socio-environmental parameters pertinent to the economic and financial valuation of the benefits of reforestation. These parameters will serve as part of feasibility studies that determine whether similar projects up for financing by the CDM qualify for financial support and whether they will achieve technical success that brings environmental and social benefits to the various social actors involved.

KEYWORDS: greenhouse effect, carbon sequestration, mangrove swamps, Clean Development Mechanism, climate change, IPCC. 


\section{Introdução}

D rojetos de florestamento e reflorestamento de manguezais — importantes ecossistemas tropicais costeiros - com a finalidade de aferir o valor de resgate do seqüestro de carbono atmosférico e de contribuir para a minimização do efeito estufa, devem estabelecer parâmetros e metodologia necessários para o seu desenho, a sua execução e a sua avaliação. Esta nota de pesquisa apresenta uma discussão pertinente, no âmbito de um projeto pioneiro de pesquisa e experimentação, em andamento, intitulado Reflorestamento de Manguezais e o Valor de Resgate do Seqüestro do Carbono Atmosférico.

Além da contribuição para o seqüestro do carbono atmosférico, nas iniciativas de reflorestamento devem ser considerados os valores agregados às atividades socioeconômicas desenvolvidas pelas comunidades humanas que habitam o entorno das áreas dos projetos. Os parâmetros devem referir-se tanto a variáveis biofísicas (volume de carbono seqüestrado na biomassa formada, uso de espécies apropriadas, biodiversidade vegetal e animal, taxas de sobrevivência e de crescimento dos espécimes plantados, salinidade, solos etc.) quanto a variáveis socioeconômicas (serviços ambientais, trabalho remunerado e voluntário, restauração de atividades produtivas, usos alternativos das terras afetadas, níveis de vida médios dos habitantes etc.). O objetivo geral desses projetos deve contemplar o uso de parâmetros socioeconômicos e ecológicos para o desenho de uma metodologia de aferição do seqüestro de carbono.

Assim, o projeto em andamento funciona como um estudo de viabilidade que servirá para ajudar no desenho e na execução de outros projetos voltados para a geração de créditos de redução de emissões, através do chamado mecanismo de desenvolvimento limpo (MDL) em áreas de florestamento e reflorestamento com espécies nativas do manguezal. Pretende-se sinalizar os princípios que orientem objetivos e metas para esses projetos, que podem ser aplicados também a outros biomas (como, por exemplo, cerrados e florestas tropicais).

\section{Manguezais de Niterói: um projeto para estudo de caso}

As atividades do projeto Manguezais de Niterói, executadas desde 1993 pela Ong APREC Ecossistemas Costeiros (<www.aprec.org.br >), compreendem trabalhos de plantio, monitoramento de áreas plantadas, vistorias semanais e atividades de educação ambiental. A área de atuação é no entorno da laguna de Itaipu, região oceânica de Niterói, no estado do Rio de Janeiro. A equipe do projeto realiza eventos que estimulam a participação de escolas, Ongs, associações de moradores, pescadores, universitários e da comunidade local em torno da educação ambiental e preservação daquele ecossistema costeiro. O projeto Manguezais de Niterói ganhou notoriedade, sendo eleito pela revista 
Super Interessante (jun. de 2002), da Editora Abril, um dos três melhores projetos do país na categoria Flora/Ong, no prêmio SuperEcologia 2002.

Esse projeto atualmente fornece dados primários necessários a outro projeto, recentemente aprovado e financiado pelo Fundo Nacional do Meio Ambiente (FNMA), o Reflorestamento de Manguezais e o Valor de Resgate do Seqüestro de Carbono Atmosférico. O objetivo deste segundo projeto é a avaliação do valor de resgate do seqüestro de carbono atmosférico em áreas degradadas reflorestadas com espécies nativas de manguezais. O projeto conta com as seguintes parcerias para sua execução: Centro de Energia Nuclear para a Agricultura da Universidade de São Paulo (CENA/USP), Centro de Pesquisas em Economia Aplicada da Escola Superior de Agricultura Luiz de Queiroz da Universidade de São Paulo (CEPEA/ESALQ) e Centro de Desenvolvimento Sustentável da Universidade de Brasília (CDS/UnB).

Parte do bosque reflorestado pelo primeiro projeto, de um hectare, com cerca de dez mil mudas (de um total de três hectares plantados com cerca de 18 mil propágulos/mudas), está servindo como referência para um estudo de caso sobre a viabilidade do reflorestamento de áreas de manguezais e dos parâmetros socioeconômicos e ecológicos envolvidos na mitigação do efeito estufa em nosso planeta. Esta nota de pesquisa discorre sobre a concepção e o desenvolvimento preliminar do segundo projeto.

\section{A escolha do cenário de referência na laguna de Itaipu}

O estudo de caso contido no projeto Reflorestamento de Manguezais e o Valor de Resgate do Seqüestro do Carbono Atmosférico será baseado em ações e observações a serem feitas na orla da laguna de Itaipu, aprovado pelo edital 09/2001 do Fundo Nacional do Meio Ambiente do Ministério do Meio Ambiente (FNMA/ MMA), com apoio do governo dos Países Baixos (Fonseca, 2001a). Desde 1993, a APREC Ecossistemas Costeiros desenvolve, desde 1993, bases de dados pertinentes e vem criando laços com a comunidade local. Colaborou com diversos órgãos públicos no sentido do conhecimento, preservação e recuperação das suas águas e do seu entorno, iniciando a recuperação de uma área de três hectares de manguezal.

O projeto Manguezais de Niterói faz parte de uma grande rede de iniciativas do Ministério do Meio Ambiente, com apoio do Instituto Brasileiro do Meio Ambiente e dos Recursos Naturais Renováveis (Ibama), em prol dos manguezais da bacia da baía de Guanabara e áreas litorâneas vizinhas alteradas ou pressionadas por ações antrópicas de diversos tipos, em particular por derramamentos acidentais de petróleo e derivados, poluição doméstica e industrial e outras. Vários organismos governamentais e não-governamentais trabalham no Brasil com esses 
ecossistemas, financiados indiretamente pelas multas pagas pela Petrobrás e por outros recursos. Através do compartilhamento de informações, procedimentos e objetivos, será possível extrapolar os achados da área de aplicação do estudo de caso do projeto Reflorestamento de Manguezais, considerando-a uma amostra significativa de uma área bem maior na qual estejam sendo desenvolvidas ações semelhantes.
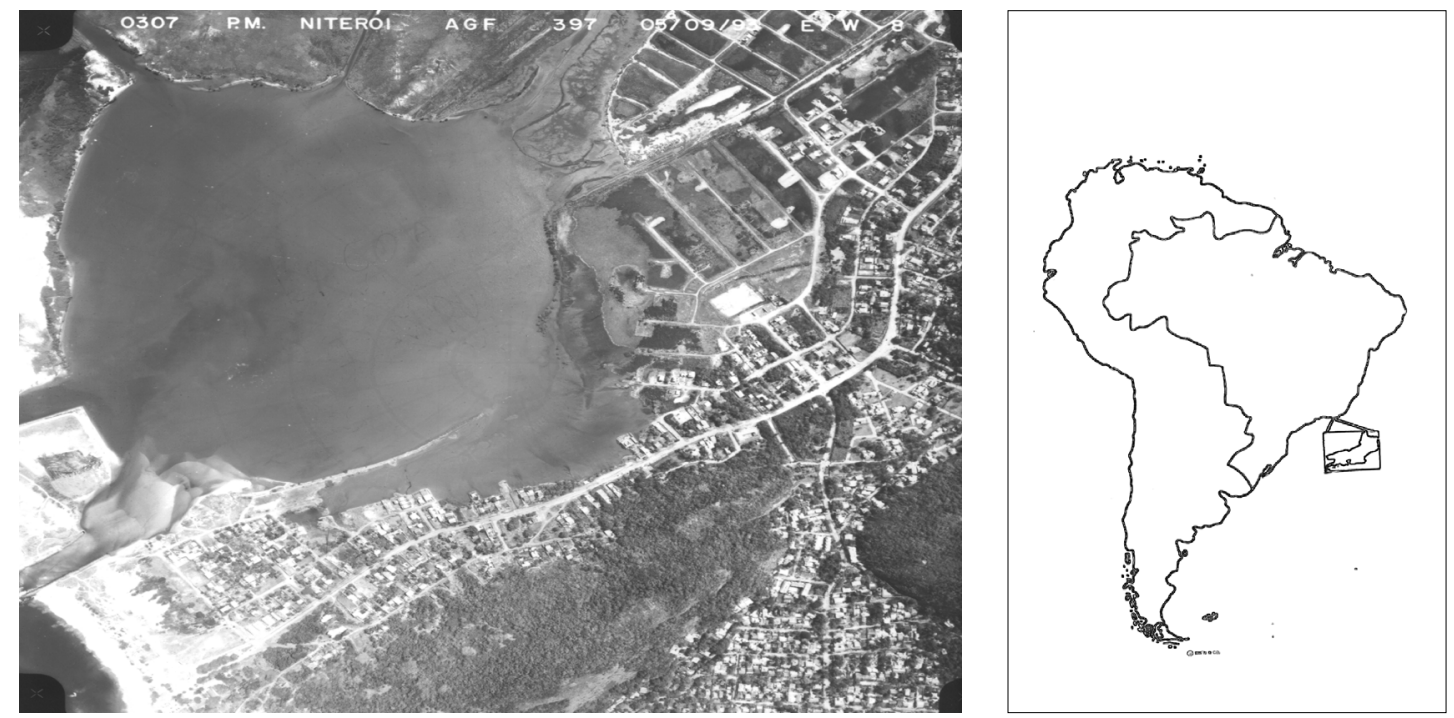

Figura 1 - Cenário de referência em 1993.

\section{Recuperação de manguezais: benefícios e beneficiários}

Apesar da proteção integral prevista pelos dispositivos legais vigentes, os manguezais brasileiros em geral vêm sofrendo um intenso e constante processo de degradação, que muitas vezes compromete os importantes serviços ambientais e econômicos que eles prestam e, por conseqüência, os estudos relacionados à sua valoração. Isso não tira, no entanto, a sua relevância para os esforços governamentais e sociais de alcançar qualidade ambiental.

Os manguezais são ecossistemas tipicamente tropicais, presentes em quatro continentes e seis regiões geográficas do planeta. As regiões de maior ocorrência são América Central e Caribe, Índia, península da Indochina, Brasil e Austrália. São compostos por árvores e arbustos que crescem em zona costeira protegida, planícies e praias lodosas, desembocaduras de rios, pertencendo a familias que apresentam grande tolerância a águas salgadas ou salobras. Os manguezais prosperam em regiões com temperaturas elevadas, altas precipitações e terrenos apropriados.

Por milhares de anos os povos costeiros dos trópicos têm se aproveitado amplamente dos bosques e seus produtos. Muitas comunidades humanas 
dependem dos manguezais para a sobrevivência e utilizam uma gama de recursos naturais provenientes do ecossistema e suas águas circundantes. Há um equilíbrio entre os bosques de manguezais e as demandas dos habitantes tradicionais que residem nas suas vizinhanças. Essas pessoas geralmente se utilizam dos manguezais sem provocar distúrbios na sua intrincada teia produtiva. Historicamente, a pressão antrópica sobre os manguezais tem sido muito forte, mesmo considerando que na concepção de algumas pessoas tais lugares são inóspitos, insalubres e perigosos. Não eram de fácil acesso e poucos se aventuravam neles, até a chegada das indústrias imobiliária e da carcinocultura.

Ultimamente, devido às pressões de ordem populacional, de produção de alimentos, de desenvolvimento industrial e urbano, vem ocorrendo uma destruição significativa dos manguezais em todo o mundo. À medida que cresce a busca por terras e recursos naturais, observamos as áreas de manguezais gradativamente sendo ocupadas até por projetos do Estado, agente responsável por sua preservação, visando a expansão urbana e o assentamento de populações. Os processos de degradação são fortes porque é na zona costeira dos continentes que a ocupação humana se dá com maior intensidade, submetendo conseqüentemente não só os manguezais como os demais ecossistemas litorâneos a pressões (cidades, pólos industriais, portos, aterros, complexos turísticos etc.) que muitas vezes destroem por completo o equilíbrio de extensas áreas.

A extensão atual dos bosques de mangue em nível mundial alcança apenas 160 mil a 170 mil quilômetros quadrados (cerca de quatro vezes a área do estado do Rio de Janeiro). Há estudos realizados na América Central, Ásia e Índia que detectam a perda de 1\% ao ano de área coberta por vegetação de manguezal, quando teriam sido necessários aumentos anuais de 5\% durante um período de vinte anos (1980 a 2000), para que fossem recompostas as áreas originais. Estima-se a perda anual de um milhão de hectares de manguezais em todo o planeta (Fonseca, 2001b).

Em diversas partes do mundo ocorrem, paralelamente ao processo de degradação, iniciativas de restaurar os manguezais afetados e até mesmo de propiciar a criação de novas áreas. Mais do que uma recente linha de pesquisa e de atuação dos profissionais ligados à área ambiental, as atividades de restauração/criação de manguezais simbolizam a crescente preocupação da sociedade com a importância destes ecossistemas. Eles são provedores e mantenedores da biodiversidade e sustentam várias atividades econômicas humanas - pesca artesanal, atividades turísticas e industriais - contribuindo para a qualidade de vida das populações residentes no seu entorno. A nossa ótica, no projeto em andamento, no entanto, é a de considerar que os manguezais são também grandes depósitos sinks para o seqüestro de carbono da atmosfera, contribuindo para mitigar o efeito estufa no planeta. 
Outra questão que precisa ficar clara em estudos de valoração dos bens e serviços desses ecossistemas é o motivo para efetuar trabalhos de reflorestamento ou de criação de manguezais. A inexistência de uma instituição supranacional e a indigência das medidas voltadas para eficiência econômica, face às grandes disparidades entre as rendas dos países de ambos os hemisférios, são entraves para um acordo sobre a emissão dos greenhouse gases (GHG — gases de efeito estufa). Isso realça a importância das pesquisas sobre o reflorestamento de manguezais (e outros biomas) como mecanismo específico para o seqüestro do carbono atmosférico (Fonseca, 2002). Diversas atividades produtivas diretamente dependentes dos manguezais justificam a relevância da sua valoração econômico-ecológica dos trabalhos de recomposição desses ambientes degradados. Dados sobre o balanço da produção mundial de camarão em cativeiro em 2000 (Gazeta Mercantil, 28-29-30.1.2000), atividade realizada intensivamente em áreas de florestas de mangue, situam a produção mundial de camarão em torno de 715 mil toneladas, havendo uma tendência de duplicação daquela produção até o ano de 2002.

Apesar da dificuldade de estimar o valor cultural destas florestas para aqueles que lá vivem, os manguezais fazem parte da paisagem e da vida das populações de seu entorno. A preservação e o reflorestamento de manguezais acarretam uma lista bem conhecida de benefícios para um público variado, especialmente quando eles ocorrem em áreas de elevada densidade populacional, como é o caso da laguna de Itaipu. Tais ações estabilizam litorais e estuários; protegem contra enchentes; protegem áreas de reprodução e criação de peixes e crustáceos e assim preservam cadeias tróficas marinhas; abrigam aves residentes e migratórias. Grupos beneficiados incluem pescadores artesanais, moradores de bairros litorâneos e ribeirinhos, turistas, enfim, toda a população local e a flutuante.

Os indicadores e os usufrutos aqui arrolados buscam destacar a importância de usos e costumes nas regiões de manguezais compatíveis com o potencial local inexplorado. Entretanto, as comunidades residentes nos entornos de manguezais, tipicamente de baixo poder aquisitivo, vivem em situação precária, pouco desfrutando de seu potencial, contrastando com a riqueza do ambiente, subvalorizado por causa da ausência de políticas públicas para o desenvolvimento sustentável, para o gerenciamento dos manguezais, enfim, para a adequada valoração dos manguezais.

\section{Manguezais e a expansão da indústria do petróleo no estado do Rio de Janeiro}

A recuperação e o reflorestamento de ecossistemas degradados ainda são atividades pouco desenvolvidas, mesmo em países altamente desenvolvidos e/ou cujos territórios predominantemente temperados 
sofreram impactos antrópicos extensos e profundos. Mesmo no caso dos ecossistemas temperados (dominantes nos países desenvolvidos), comparativamente mais simples em termos de componentes, estruturas e processos, e quase sempre mais intensivamente estudados pela ciência, a recuperação de ecossistemas é uma atividade relativamente rara e pontual que compete por recursos e pela atenção da comunidade científica com políticas preventivas de preservação e conservação. A situação é ainda mais crítica em países tropicais pobres e/ou em desenvolvimento, pois a maior complexidade dos ecossistemas tropicais convive com um estado geral do conhecimento científico muito inferior ao que existe sobre os ecossistemas temperados. Além do mais, em geral os países tropicais têm recursos limitados para dedicar tanto a políticas preventivas quanto a políticas de recuperação de ecossistemas.

Os manguezais, como formações típicas dos trópicos, localizados estrategicamente na interface de massas terrestres e oceânicas, formam um bioma ideal para o desenvolvimento do conhecimento científico capaz de auxiliar no desenho de políticas preventivas e recuperadoras a serem desenvolvidas em ambiente socioeconômico de elevada complexidade (na proximidade de cidades, portos, fábricas, estuários etc.). No caso do litoral do estado do Rio de Janeiro, os seus manguezais combinam uma longa história de exploração extensa e irracional com as ameaças mais recentes e de grande escala ligadas à exploração petrolífera e ao transporte, refino e industrialização do petróleo. Além de o estado ser um grande importador, consumidor e transformador de petróleo e derivados, ele é de longe o líder nacional de produção de petróleo. Toda essa produção vem de campos e poços submarinos, o que coloca grandes trechos do litoral fluminense (inclusive os seus manguezais) sob o risco cotidiano de acidentes envolvendo derrames de petróleo cru. As grandes reservas medidas no litoral fluminense ao longo dos últimos vinte anos e a forte incidência de novas áreas recentemente licitadas para prospecção indicam que essa liderança será mantida e até ampliada nas próximas décadas. Essa situação, juntamente com as ações em curso de recuperação de manguezais fluminenses, citadas anteriormente, conferem uma relevância singular a iniciativas de estudar os princípios e procedimentos de reflorestamento de manguezais no litoral do estado do Rio de Janeiro.

\section{Viabilidade de projetos para reflorestamento de manguezais para fins de seqüestro do carbono atmosférico}

O estudo da viabilidade de projetos desse tipo deve identificar oportunidades de investimentos financeiros e de transferência de tecnologias, previstos na Convenção do Clima e no Protocolo de Quioto. O Protocolo de Quioto prevê a formação de um mercado internacional em que o seqüestro de carbono, promovido pelo crescimento de florestas, 
pode ser transformado em títulos negociáveis entre governos e empresas dos países signatários, entre os quais está o Brasil. O nosso projeto pretende oferecer aos interessados uma perspectiva precisa de como conduzir as atividades de reflorestamento para que obtenham os benefícios do Protocolo de Quioto, participando efetivamente do emergente mercado de carbono.

Para que um projeto de reflorestamento possa ser contemplado e participar no mencionado mercado, são necessários estudos detalhados sobre as projeções de acúmulo de carbono (na forma de biomassa vegetal), para permitir uma quantificação precisa dos estoques existentes e dos que serão formados. Além disso, é necessário cumprir requisitos de elegibilidade, previstos no protocolo, principalmente o da adicionalidade e de vazamento. $\mathrm{O}$ critério adicionalidade refere-se a uma comparação entre o que o projeto se propõe a realizar e o que aconteceria na ausência do projeto. O critério de vazamento refere-se à probabilidade (indesejada) de uma atividade seqüestradora específica num local promover emissões de carbono noutro local.

Uma vez verificada a adicionalidade, ela poderá ser certificada sob os critérios do Protocolo de Quioto e, conseqüentemente, ser transformada nos denominados certificados de redução de emissões (CREs), que são o primeiro passo para a obtenção dos títulos negociáveis no mercado formal. Esses critérios estão sendo discutidos tanto no nível internacional (IPCC e COP) quanto no Brasil, pelo Ministério da Ciência e Tecnologia e uma comissão interministerial e grupos de interesse.

\section{A contribuição do estudo de caso}

O projeto Reflorestamento de Manguezais e o Valor de Resgate do Seqüestro do Carbono Atmosférico está contribuindo com os primeiros aportes de conhecimento técnico-científico e de bases para o desenho de políticas públicas e ações comunitárias, no sentido de viabilizar a recuperação e o reflorestamento de ecossistemas costeiros degradados, acoplados a benefícios socioeconômicos gerados para os atores envolvidos. Ele está contribuindo para o estabelecimento de metodologia de aferição do carbono atmosférico seqüestrado em projetos de ação climática, mitigando problemas advindos do efeito estufa, e contabilizando o valor socio econômico-ecológico agregado por essas ações.

Este estudo de caso vai gerar dados e análises sobre o potencial de seqüestro de carbono em projetos de reflorestamento. Ele formatará as informações existentes sobre projetos de reflorestamento e desenvolverá uma discussão sobre as bases técnicas a serem utilizadas para que projetos em grande escala sejam considerados elegíveis a participar do mercado de carbono com base no Protocolo de Quioto, a saber: MDL e os certificados de redução de emissões (CDM/CRE). 
Isso compreende: estabelecimento de metodologia para aferição do carbono atmosférico seqüestrado em reflorestamentos de manguezais; cálculo do valor dos créditos para contabilização e emissão dos certificados de emissões reduzidas (CERs); estabelecimento de indicadores de sustentabilidade do valor socioeconômico-ecológico agregado pelas ações de projetos de ação climática, denominados indicadores do carbono social (ICS).

\section{Metas para o cálculo dos créditos para contabilização e emissão dos CERs}

O estudo de caso deve utilizar instrumental econométrico associado à biometria — basicamente a medição das quantidades de biomassa vegetal gerada - das amostras de espécies da flora de manguezal. Esta atividade é inédita e o seu objetivo é a definição metodológica, para determinar o potencial da participação e/ou estabelecimento do mercado de carbono seqüestrado em projetos de reflorestamento de manguezais, para captação de recursos em LULUCF (Land Use, Land Use Change and Forestry). O estudo deve determinar o potencial de geração de créditos passíveis de comercialização por projetos de reflorestamento de manguezais, a partir de critérios que satisfaçam as exigências de elegibilidade do Protocolo de Quioto/Acordo de Marrakech.

\section{Indicadores do Carbono Social}

Para o estabelecimento de um instrumento econômico-ecológico (IEE) para a gestão socioambiental de projetos de reflorestamento, aqui também denominado como indicador do carbono social (IEE-CS), o estudo de caso fará extenso levantamento bibliográfico sobre índices e indicadores e sobre a legislação de qualidade ambiental e da vida humana, como respaldo para estudar o impacto das atividades antrópicas no meio ambiente. O objetivo é uma melhor definição da qualidade de vida e da relação entre as atuais gerações e os ecossistemas, contribuindo com instrumental metodológico na formação de indicadores de desenvolvimento humano e ambiental, em atividades de reflorestamento para o seqüestro do carbono atmosférico. Em princípio, esses indicadores seguirão duas dimensões principais: qualidade de vida das populações residentes e/ou envolvidas, medida a partir de seu acesso (real e desejado) a bens de consumo e a serviços públicos selecionados; e valores associados aos usos alternativos que poderiam ser dados às áreas objeto de recuperação e florestamento. 


\section{Metas da metodologia para aferição do carbono atmosférico seqüestrado}

Serão perseguidas as seguintes metas:

- investigação dos teores do carbono e nutrientes do solo de manguezal e da vegetação e possível influência no seqüestro de carbono via fotossíntese;

- coleta e envio de amostras de solo e vegetais para análises;

- quantificação do carbono seqüestrado e de ciclagem de outros nutrientes no sistema.

Para as análises de amostras de solo e vegetais, as metas específicas são as seguintes:

- Solo - coletas periódicas de amostras de solo e da lama para análises: de rotina para fins de fertilidade (métodos Embrapa e IAC) ( $\mathrm{pH}$, matéria orgânica, $\mathrm{P}, \mathrm{K}, \mathrm{Ca}, \mathrm{Mg}, \mathrm{Al}+\mathrm{H}$ ); e de outros elementos de interesse: $\mathrm{N}$, S e alguns micronutrientes (Fe, $\mathrm{Cu}, \mathrm{Zn}$ e $\mathrm{Mn}$ ). Os nutrientes devem ser analisados quanto aos teores totais e às formas disponíveis

- Vegetais - amostras de espécies vegetais predominantes no manguezal devem ser analisadas quanto ao conteúdo de C, N, P, K, $\mathrm{Ca}, \mathrm{Mg}, \mathrm{S}, \mathrm{Fe}, \mathrm{Cu}, \mathrm{Zn}, \mathrm{Mn}$ e B. Para tanto, as plantas devem ser separadas em folhas, caules, frutos ou flores e raízes.

\section{Conclusão}

O estudo deve alcançar a determinação do potencial de mercado de carbono para LULUCF, a determinação da geração de créditos de comercialização com base no Protocolo de Quioto, mecanismo de desenvolvimento limpo, certificados de redução de emissões, e ainda:

a) Discussão dos mercados atuais e cenários futuros (potenciais);

b) Formatação das bases para um projeto carbono nos conhecimentos atuais do assunto: IPCC (Intergovernamental Panel on Climate Change), COP (Conferência das Partes) e governo brasileiro (Comissão Interministerial para Mudanças Climáticas);

c) Discussão das características encontradas nas áreas do projeto, dentro do arcabouço de critérios técnicos a serem utilizados no processo de certificação, e da elegibilidade de acordo com o Protocolo de Quioto (projeções de acúmulo de carbono, adicionalidade, vazamento, capacidade etc.);

d) Estimativa da linha de base (baseline): comportamento dos estoques de carbono na ausência de qualquer iniciativa relativa ao MDL;

e) Estimativas de seqüestro de carbono em projetos de reflorestamento: tipificação das oportunidades relacionadas às atividades de reflorestamento; 
Agradecemos a Marcelo Theoto Rocha (CEPEA/ ESALQ/USP) e Takashi Muraoka (CENA/ESALQ/ USP) pelas leituras críticas e sugestões feitas a trechos de uma versão anterior deste trabalho. f) Avaliação dos potenciais do projeto frente aos critérios de elegibilidade do Protocolo de Quioto, e/ou do mercado de carbono.

Ao ampliar a base de conhecimento técnico-científico exigido para o desenho de políticas públicas e ações, o estudo de caso em curso viabiliza a recuperação e reflorestamento de ecossistemas costeiros degradados e mede benefícios socioeconômicos a serem auferidos pelos atores envolvidos. Contribui ainda para o estabelecimento de metodologia para aferição do carbono atmosférico seqüestrado em projetos de ação climática de grande escala, capazes de gerar benefícios socioeconômicos mensuráveis para as populações vizinhas e/ou envolvidas e de mitigar problemas advindos do efeito estufa em nosso planeta. Será uma contribuição importante para que diversos atores brasileiros - governos, consórcios municipais, associações de produtores, ONGs, empresas, investidores - possam atuar neste mercado global emergente com um destaque proporcional à grande importância que o Brasil desfruta no panorama dos países com vocação para a produção de biomassa vegetal.

\section{REFERÊNCIAS BIBLIOGRÁFICAS}

Fonseca, Sérgio de Mattos

2002

Fonseca, Sérgio de Mattos

$2001 \mathrm{a}$

Fonseca, Sérgio de Mattos

$2001 b$

Gazeta Mercantil 23.1.2000

Revista Super Interessante jun. 2002
Reflorestamento de ecossistemas manguezais como contribuição ao seqüestro do carbono atmosférico. Projeto de tese de doutoramento, Rio de Janeiro. (mimeo.)

Projeto Reflorestamento de Ecossistemas de Manguezais e o Valor de Resgate do Seqüestro do Carbono Atmosférico. Projeto apresentado ao Edital 9/2001, Rio de Janeiro, Fundo Nacional do Meio Ambiente (FNMA). (mimeo.)

O valor de existência de um ecossistema costeiro tropical, através da disposição ao trabalho voluntário. Dissertação de mestrado, Niterói, PPGCA/Universidade Federal Fluminense.

'A indústria do pescado'. Rio de Janeiro.

Rio de Janeiro, $\mathrm{n}^{\circ} 177$. 